\title{
Findings About Events or Interventions Character Result in Standard Format
}

National Cancer Institute

\section{Source}

National Cancer Institute. Findings About Events or Interventions Character Result in

Standard Format. NCI Thesaurus. Code C113368.

The standard character or string for representation and reporting of findings about events or interventions data. 